\title{
Sexual Compulsivity, the Internet, and Sexual Behaviors Among Men in a Rural Area of the United States
}

\author{
Phillip W. Schnarrs, M.A., Joshua G. Rosenberger, M.P.H., Ph.D.(c), ${ }^{1,2}$ \\ Sonya Satinsky, M.P.H., Ph.D., Emily Brinegar, M.S.W., Jill Stowers, M.S.W., \\ Brian Dodge, Ph.D., M.S., and Michael Reece, Ph.D., M.P.H.1
}

\begin{abstract}
Sexual compulsivity has been associated with higher frequencies of sexual behaviors that may increase risk for transmission of HIV and other sexually transmitted infections (STI). In a rural midwestern region where social and community resources for the sexual health of men who have sex with men (MSM) are relatively few, the patterns of partner-seeking and sexual behavior, and their relations to sexual compulsivity, may be different than findings from other assessments of men in urban centers. Using a community-based participatory approach (CBPR), data were collected from 309 men who were primarily white, identified as gay or homosexual, and had a mean age of 29.37 years $(\mathrm{SD}=11.33)$, to explore relations between scores on a measure of sexual compulsivity and their sexual partner-seeking, drug and alcohol use, and sexual behaviors with men and women. The majority of men reported having engaged in sexual activity with men in the past 30 days. Those scoring higher than the sample mean $(1.65[\mathrm{SD}=0.66])$ on the sexual compulsivity measure reported patterns of having sex with partners met online and having been the insertive or receptive partner in unprotected anal intercourse. Given the unique patterns of sexual partner-seeking in this area, interventions to decrease sexual risk-taking should take into account that the vast majority of men in rural areas are using the Internet to locate sexual partners, and prevention messages focused on rural contexts need to be tailored to include men who have a propensity for sexually compulsive behaviors. Additionally, interventions created for virtual spaces may be more sustainable with rural communities than traditional approaches to HIV/STI prevention.
\end{abstract}

\section{Introduction}

Since the beginning of the HIV epidemic, researchers Whave sought to understand the sexual lives of men who have sex with men (MSM) and the factors associated with HIV incidence among this population, given the extent to which they have disproportionately been impacted. ${ }^{1-6}$ The majority of research focusing on HIV infection and its prevention among MSM has historically focused on urban men, ${ }^{1-6}$ with less attention having been devoted to MSM residing in rural areas; studies among these men have primarily focused on those residing in areas with little to no access to sexual health resources. ${ }^{7-13}$

Consistent throughout the literature on MSM and behaviors likely to result in HIV transmission is a line of research focused on compulsive sexual behavior. ${ }^{13-18}$ However, consistent with other research on MSM, the majority of studies examining relations between sexual compulsivity and HIV risk behavior have primarily been focused on MSM residing in urban areas.

Sexual compulsivity has been characterized as a propensity to engage in sexually related activities that occur at escalating levels and have the potential to result in negative consequences to one's self or others, with higher scores on measures of sexual compulsivity indicative of one's preoccupation with sex and perceived lack of control over their sexual impulses. ${ }^{14-19}$ Consistent across prior work in this area are relations between higher sexual compulsivity scores and an increased likelihood that one will report participation in sexual behaviors that pose the potential for HIV and other sexually transmissible infections (STI), particularly among MSM. ${ }^{14,16,17,20-33}$ Previous work in this area has focused on a range of groups, including those who identify as heterosexual, ${ }^{14,26,34}$ individuals living with $\mathrm{HIV},{ }^{27-32}$ urban

\footnotetext{
${ }^{1}$ Indiana University, Center for Sexual Health Promotion, Bloomington, Indiana.

${ }^{2}$ Indiana University, School of Medicine, Division of Adolescent Medicine, Indianapolis, Indiana.

${ }^{3}$ Positive Link, Bloomington Hospital, Bloomington, Indiana.
} 
$\mathrm{MSM}^{35}$ and clinical samples of individuals seeking STI treatment. $^{39}$

Additionally, higher scores on measures of sexual compulsivity have been associated with one's choice of venues for seeking and finding sexual partners, particularly the likelihood that one will seek partners in sex-specific venues. ${ }^{35}$ Among the measures most frequently used to measure sexual compulsivity is the Sexual Compulsivity Scale (SCS), ${ }^{37}$ for which reliability and validity have been established across a range of samples. ${ }^{16,29,33,36,42-48}$

While some have examined relations between the venues in which MSM seek sexual interactions and sexual compulsivity, few have focused on the Internet as a sexual venue for rural MSM. Unlike major metropolitan areas where several locations for finding potential sexual partners (e.g., gay bars, gay and lesbian community centers, bath houses) may exist, men living in rural communities may be limited to public venues (known as cruising spots) and the Internet to find social and sexual connections. Research examining rural MSM's use of the Internet for finding sexual partners has documented that heightened social conservatism, homophobia, and heteronormative values increase the likelihood of this population using the Internet to find sexual partners, a greater degree of internalized homophobia, as well as higher rates of sexual activities that may lead to STI or HIV infection. ${ }^{48-50}$ Studies assessing relations between the Internet and sexual compulsivity have focused primarily on issues such as viewing pornography, ${ }^{51,52}$ time spent online on sexually related websites, ${ }^{53}$ online relationships, ${ }^{54}$ and online infidelity. ${ }^{54}$ However, while the Internet as a venue for sexual partner seeking among MSM has been established, ${ }^{35,56-59}$ few studies have examined relations between sexual compulsivity and using the Internet for finding sexual partners, as well as the subsequent sexual behaviors of men who meet partners online.

The purpose of this study was to assess the sexual behaviors of men (primarily MSM) living in a rural midwestern area of the United States, their patterns of sexual partner seeking across a range of venues, and potential associations between these behaviors and their scores on a measure of sexual compulsivity. An understanding of these issues among men in such geographic areas will be helpful to those focused on the development and implementation of public health programs designed to decrease the incidence of HIV and STI infection among men in rural areas.

\section{Methods}

\section{Participatory nature of this study}

This study was conducted under the auspices of a partnership between academic researchers and representatives of a local community-based organization that serves as the primary provider of HIV-related prevention and care services to individuals in seven rural counties in Indiana. This study was specifically developed for the purpose of informing the programmatic directions of the organization's HIV prevention efforts. The principles of community-based participatory research, as articulated by Israel and colleagues, ${ }^{60}$ were operationalized for this study in accordance with guidelines provided by Reece and Dodge, ${ }^{61}$ to ensure that community members and academic researchers worked in a participatory and equitable manner to design the study protocols and in- struments, collect and analyze data, and interpret data for the purposes of dissemination and integration into the organization's programs.

\section{Participant recruitment and data collection}

To recruit a diverse group of MSM within the community under study, multiple recruitment strategies were used, including face-to-face recruitment, Internet-based recruitment, and flyer and palm card recruitment. For face-to-face recruitment, research assistants approached men at community venues where MSM were likely to be receiving some type of service, particularly at HIV testing sites and at the local offices of an AIDS service organization. A trained research assistant utilized a script to invite men to participate in an anonymous survey about sexual behavior. Men who had an interest in learning more about the study had two options: (1) to take the survey online via a laptop that was connected to the Internet and that was available in a private room at the outreach site or (2) men received a "palm card" with the Internet address of the study and could subsequently take the survey in a location of their choosing. For Internet recruitment, advertisements inviting participation in the research study were posted in online forums frequented by MSM, and on the websites of local resources for MSM. Men who viewed these advertisements could click on a link to go to the secure study website, review information about the study, and decide whether to participate. Flyer and palm cards that provided information about the study were posted by research assistants at local retail sites and venues, such as bars, coffee shops, and bookstores. These advertisements contained the link to the study website where men could learn more about the study and decide whether to participate.

All participants were male and over the age of 18. All data were collected via the Internet and participants were offered the chance to provide their email address (which was recorded in a database separate from responses to survey items) to be entered into a lottery to win one of forty $\$ 50$ Visa gift cards. All study protocols were reviewed and approved by the Institutional Review Board at Indiana UniversityBloomington.

\section{Measures}

Participant characteristics. Participants provided data related to their age, gender (male, female, transgender male to female, transgender female to male, or other), race/ethnicity, level of education completed, employment status and housing situation. Participants also responded to items related to their relationship status (married, partnered, divorced, widower, single, and other); whether they were currently dating someone or in a relationship (in a relationship with the same person longer than 6 months, 3-6 months, less than 6 months, dating more than one person, or not dating anyone); and whether they were currently in a sexual relationship (with one person, more than one person, sexually active, but do not consider myself in a sexual relationship, or currently not sexually active).

Sexual behaviors. Participants were asked to indicate whether or not they had engaged in specific unprotected (without a condom) sexual behaviors with both women and men over the previous 90 days. Unprotected behaviors 
included receptive anal intercourse, insertive anal intercourse, insertive vaginal intercourse, and performing or receiving oral sex. Additionally, participants reported (via a dichotomous yes/no response option) whether or not they had visited or utilized sexualized venues and resources in the previous 90 days. These venues included sex-related Internet sites, telephone chat lines, cruising spots such as parks or restrooms, bath houses or sex clubs, and gay bars.

Sexual compulsivity. Sexual compulsivity was measured using the 10-item Sexual Compulsivity Scale. ${ }^{37}$ Sample items included "My sexual appetite has gotten in the way of my relationships," "I sometimes fail to meet my commitments and responsibilities because of my sexual behaviors," and "I feel that my sexual thoughts and feelings are stronger than I am." The items were measured on a four-point Likert-type scale ranging from 1 (never) to 4 (always). ${ }^{37}$

\section{Results}

\section{Participant characteristics}

Three hundred nine men completed the survey. Of those, 55\% $(n=170)$ identified their sexual orientation as homosexual/gay, $19.7 \%(n=61)$ as bisexual, and $16.5 \%$ $(n=51)$ as heterosexual/straight, with the remaining participants indicating they were unsure/questioning or other $(5.9 \%, n=16)$. The mean age of participants was 29.37 years $(\mathrm{SD}=11.33)$, with a range of 18 to 67 years. The majority of the sample identified their ethnicity as white $(89.6 \%, n=277)$, with small proportions reporting other ethnicities, including $2.6 \%(n=8)$ who identified as African American/black or of another race and $2.3 \%$ as Hispanic/Latino. The demographic data concerning race and ethnicity closely match the demographic profile of the rural setting where the research was situated. The majority $(81.2 \%, n=251)$ of participants indicated they resided in the largest city (population of 69,291 persons) in the area where the study was conducted, with the remaining participants being from either surrounding communities of that area $(12.0 \%, n=39)$ or other areas in and outside of the state $(2.6 \%, n=8)$.

Most $(63.8 \%, n=197)$ of the respondents described themselves as single. The remaining participants identified as married $(9.4 \%, n=29)$, partnered $(18.1 \%, n=56)$, divorced $(4.9 \%, n=15)$, widowed $(0.3 \%, n=1)$, or identified with another type of relationship status $(1.6 \%, n=5)$. When participants were asked if they were currently dating someone or in a relationship, $52.8 \%(n=163)$ indicated they were not, $31.1 \%$ $(n=96)$ were currently in a relationship with the same person for longer than 6 months, $2.9 \%(n=9)$ had been in a relationship with the same person for 3-6 months, $4.2 \%(n=13)$ were currently in a relationship with the same person for less than 3 months, and $7.1 \%(n=22)$ had been dating more than one person.

Regarding sexual relationships, $26.5 \%(n=82)$ indicated they were currently in a sexual relationship with only one person and $20.1 \%(n=62)$ considered themselves to be in a sexual relationship with more than one person. The majority $(82.2 \%, n=254)$ had at least a high school level of education, slightly more than half $(53.1 \%, n=164)$ of the respondents indicated they were college students, and $43.7 \%(n=135)$ were not college students. The demographics of participants are summarized in Table 1.
Table 1. Participant Characteristics $(n=309)$

\begin{tabular}{|c|c|c|}
\hline \multirow[b]{2}{*}{ Characteristics } & \multicolumn{2}{|c|}{ Total sample } \\
\hline & $\mathrm{n}$ & $\%$ \\
\hline \multicolumn{3}{|l|}{ Age $(n=309)$} \\
\hline $18-23$ & 149 & 48.2 \\
\hline $24-29$ & 44 & 14.2 \\
\hline $30-39$ & 43 & 13.7 \\
\hline $40-49$ & 48 & 15.4 \\
\hline $50-59$ & 14 & 4.5 \\
\hline $60+$ & 6 & 2.1 \\
\hline No response & 5 & 1.6 \\
\hline \multicolumn{3}{|l|}{ Education $(n=309)$} \\
\hline Less than high school & 43 & 13.9 \\
\hline High school or GED & 147 & 47.6 \\
\hline Some college or Associates & 58 & 18.8 \\
\hline Bachelor's degree & 35 & 11.3 \\
\hline Master's degree & 13 & 4.2 \\
\hline Professional & 1 & 0.3 \\
\hline Other & 12 & 3.9 \\
\hline \multicolumn{3}{|l|}{ Race/ethnicity $(n=309)$} \\
\hline African American/Black & 8 & 2.6 \\
\hline White & 277 & 89.6 \\
\hline Hispanic/Latino & 7 & 2.3 \\
\hline Asian/Pacific Islander & 4 & 1.3 \\
\hline Other & 13 & 4.2 \\
\hline \multicolumn{3}{|l|}{ Sexual orientation $(n=309)$} \\
\hline Heterosexual/straight & 51 & 16.5 \\
\hline Homosexual/gay & 170 & 55 \\
\hline Bisexual & 61 & 19 \\
\hline Unsure/questioning & 15 & 4.9 \\
\hline Other & 3 & 1 \\
\hline No response & 9 & 2.9 \\
\hline \multicolumn{3}{|l|}{ Relationship status $(n=309)$} \\
\hline Married & 29 & 9.4 \\
\hline Partnered & 56 & 18.1 \\
\hline Divorced & 15 & 4.9 \\
\hline Widowed & 1 & 0.3 \\
\hline Single & 197 & 63.8 \\
\hline Other & 14 & 4.5 \\
\hline No response & 5 & 1.6 \\
\hline \multicolumn{3}{|l|}{$\begin{array}{l}\text { Current sexual relationship } \\
(n=309)\end{array}$} \\
\hline $\begin{array}{l}\text { Sexual relationship with only } \\
\text { one person }\end{array}$ & 82 & 26.5 \\
\hline $\begin{array}{l}\text { Sexual relationships with more } \\
\text { than one person }\end{array}$ & 62 & 20.1 \\
\hline $\begin{array}{l}\text { Sexually active, but not in } \\
\text { a sexual relationship }\end{array}$ & 94 & 30.4 \\
\hline Currently not sexually active & 60 & 19.4 \\
\hline No response & 11 & 3.6 \\
\hline
\end{tabular}

\section{Sexual behaviors}

The majority of men $(65.6 \%, n=168)$ indicated they had engaged in sexual activity with men, and $24.3 \%(n=75)$ with women, in the past 30 days. In terms of sexual orientation, $79.9 \%(n=123)$ of self-identified homosexual/gay men indicated sexual activity with a man in the past 30 days, as did $72.2 \%(n=39)$ of bisexual men, $54.5 \%$ of men who were unsure or questioning their sexuality, and $13 \%(n=6)$ of self identified heterosexual men. Of those men who reported sexual activity with women, $89.1 \%(n=41)$ of self identified heterosexual men reported sexual activity with women in the 
Table 2. Sexual Behaviors in the Past 30 Days

\begin{tabular}{|c|c|c|c|c|}
\hline \multirow[b]{2}{*}{ Sexual scenario } & \multicolumn{2}{|c|}{ Yes } & \multicolumn{2}{|c|}{ No } \\
\hline & $\mathrm{n}$ & $\%$ & $\mathrm{n}$ & $\%$ \\
\hline Sex with a women $(n=268)$ & 75 & 24.3 & 193 & 62.5 \\
\hline Inserted penis into a vagina $(n=268)$ & 65 & 21 & 12 & 3.9 \\
\hline Inserted penis into a vagina without a condom $(n=268)$ & 49 & 15.9 & 16 & 5.2 \\
\hline Inserted penis into a vagina with a condom $(n=268)$ & 38 & 12.3 & 27 & 8.7 \\
\hline Inserted penis into woman's anus $(n=268)$ & 11 & 3.6 & 66 & 21.4 \\
\hline Inserted penis into a woman's anus without a condom $(n=268)$ & 7 & 2.3 & 4 & 1.3 \\
\hline Inserted penis into a woman's anus with a condom $(n=268)$ & 5 & 1.6 & 6 & 1.9 \\
\hline Sexual activity with men $(n=268)$ & 176 & 65.7 & 92 & 34.3 \\
\hline Inserted penis into a man's anus $(n=268)$ & 95 & 35.4 & 84 & 31.3 \\
\hline Inserted a penis into your anus $(n=268)$ & 86 & 32.1 & 93 & 34.7 \\
\hline Inserted penis into a man's anus with a condom $(n=268)$ & 64 & 23.9 & 31 & 11.6 \\
\hline Inserted penis into a man's anus without a condom $(n=268)$ & 57 & 21.3 & 38 & 14.2 \\
\hline Inserted a penis into your anus with a condom $(n=268)$ & 55 & 20.5 & 31 & 11.6 \\
\hline Inserted a penis into you anus without a condom $(n=268)$ & 52 & 19.4 & 35 & 13.1 \\
\hline Oral sex without condoms $(n=226)$ & 170 & 75.2 & 56 & 24.8 \\
\hline
\end{tabular}

past 30 days, as did $81.8 \%(n=9)$ of men who were unsure about or questioning their sexuality, $38.9 \%(n=21)$ of bisexual men, and $1.3 \%(n=2)$ of gay men (Table 2$)$.

Additionally, of men reporting sexual interactions with other men in the past 30 days, the mean number of male sexual partners was $3.40(\mathrm{SD}=8.03)$. Approximately half $(48 \%, n=82)$ of participants indicated they had been the receptive partner in anal intercourse and $55.6 \%(n=95)$ reporting they had been the insertive partner in anal intercourse in the past 30 days. Among men reporting sexual interactions with women in the past 30 days, the mean number of female sex partners was $2.15(\mathrm{SD}=5.06)$ with $84.4 \%(n=65)$ reporting vaginal intercourse and $14.3 \%(n=11)$ indicating anal intercourse.

Among men having intercourse with male partners, 19.4\% $(n=52)$ had let another man insert his penis into his anus without a condom and $21.3 \%(n=57)$ had inserted their penis into another man's anus without a condom. Regarding condoms and sexual interactions with women, $18.3 \%(n=49)$ of those men having sexual intercourse with women had inserted their penis into a woman's vagina without a condom and $2.6 \%(n=7)$ had been the insertive partner in anal intercourse without a condom.

\section{Sexual compulsivity}

Analyses related to sexual compulsivity are limited to the $87.38 \%(n=270)$ of participants who responded to all items on the sexual compulsivity measure. Among these men, the mean SCS score was $1.65(\mathrm{SD}=0.66)$, with $40 \% \quad(n=108)$ scoring at or above the mean on the SCS. For this study men at or above the mean SCS score were considered as scoring higher on this measure of sexual compulsivity, while those men below the mean were considered to have scored lower in sexual compulsivity.

\section{Sexual compulsivity and participant characteristics}

Those scoring at or above the mean on the SCS were more likely than those scoring below the mean to report being married $\left[\chi^{2}(1,258)=6.691, p=0.10\right]$, employed 35 hours a week or more, $\left[\chi^{2}(3,258)=9.491, p=0.023\right]$, and currently in a sexual relationship with more than one person $\left[\chi^{2}(4\right.$, $258)=18.688, p=0.001]$. Sexual compulsivity scores did not differ significantly by any other sociodemographic characteristic.

\section{Sexual compulsivity and sexual behavior}

Men with higher scores on the SCS were also more likely to report a recent history of sex with other men $\left[\chi^{2}(1\right.$, $256)=4.310, p=0.038$ ] compared to participants scoring below the sample mean. Additionally, participants with higher SCS scores were also more likely to have inserted another man's penis in their anus $\left[\chi^{2}(1,83)=4.443, p=0.035\right]$, or inserted their penis into another man's anus $\left[\chi^{2}(1,95)=4.043\right.$, $p=0.044$ ] without a condom in the previous 30 days. SCS scores did not differ significantly among sexual behaviors with women.

\section{Sexual compulsivity and venues for meeting sexual partners}

Men in this study indicated they had used a range of venues for seeking or meeting sexual partners in the past 30 days. Men reported visiting gay-related Internet sites $(85.7 \%$, $n=192)$, gay bars $(30.8 \%, n=69)$, cruising spots $(8.9 \%$, $n=20)$, bathhouses or sex clubs $(4.9 \%, n=11)$, and phone chat lines $(0.9 \%, n=2)$. These results are summarized in Table 3.

Men scoring higher on the sexual compulsivity measure were more likely to report having used a phone chat line $\left[\chi^{2}\right.$ $(2,212)=6.321, p=0.042]$ or to have visited a cruising $\operatorname{spot}\left[\chi^{2}\right.$ $(2,212)=12.376, p=0.002]$. Additionally, these men were

Table 3. Venue Use in the Past 30 Days

\begin{tabular}{lrr}
\hline Venue & $\mathrm{n}$ & $\%$ \\
\hline Gay-related Internet sites $(n=270)$ & 192 & 85.7 \\
Gay bars $(n=270)$ & 69 & 30.8 \\
Cruising spots $(n=270)$ & 20 & 8.9 \\
Bathhouse or sex club $(n=270)$ & 11 & 4.9 \\
Phone chat lines $(n=270)$ & 2 & 0.9 \\
\hline
\end{tabular}


more likely to report having had sex with someone they met on the Internet $\left[\chi^{2}(2,212)=6.951, p=0.031\right]$, at a cruising spot $\left[\chi^{2}(2,212)=7.328, p=0.026\right]$, or at a gay bar $\left[\chi^{2}(2\right.$, $212)=7.328, p=.026$,) than those men with lower sexual compulsivity scores. Furthermore, men scoring higher on the SCS were more likely to have had sex with a prostitute or sex worker $\left[\chi^{2}(2,212)=6.321, p=0.042\right]$ and to have been given drugs or money for $\operatorname{sex}\left[\chi^{2}(2,212)=10.563, p=0.005\right]$.

\section{Discussion}

This study sought to understand relations between sexual compulsivity and patterns of sexual partner seeking and sexual behavior among a sample of men in a rural geographic area. The majority of research on these issues has been conducted among men in larger urban areas that often have more venues to meet potential sexual partners and more resources specifically for MSM.

Men with increased sexual compulsivity scores were more likely to report unprotected intercourse (both receptive and insertive anal intercourse) with male partners in the past 30 days, a finding that is similar to other research in this area. ${ }^{35}$ This finding contributes to the evidence from men in other areas of the country suggesting that sexual compulsivity measures may be a helpful tool for identifying those men who would benefit from targeted HIV and STI prevention efforts.

Men with increased sexual compulsivity scores were also more likely to report a history of seeking sexual partners via phone chat lines and cruising spots, although the number of men using chat lines was extremely small. However, the venues used by men who scored higher on a measure of sexual compulsivity may be unique to rural populations that do not have access to a variety of venues beyond cruising spots and the Internet. It should be noted, however, that although using the Internet for finding sexual partners was not associated with sexual compulsivity score, having sex with individuals met online was.

Additionally, sexual compulsivity scores were associated with whether or not participants had sexual interactions with individuals whom they had met in specific venues. Of particular interest was that $42.2 \%(n=89)$ of men reported sex with someone they had met online. Of this group $51.7 \%$ $(n=46)$ scored at or above the mean on the SCS. Similar results have been found with previous studies examining Internet use for finding sexual partners. ${ }^{35}$ However, considering the nature of the rural area where this study was conducted, and that the venues for finding sexual partners are limited, the Internet may be a primary source for finding sexual partners; the vast majority $(>85 \%)$ had visited gay-related Internet sites within the past 30 days.

With this in mind, future research should begin to investigate the possibility of the Internet being a primary source for finding sexual partners for individuals living in rural areas, as well as establishing a means for intervention for those men with more sexually compulsive tendencies. Furthermore, developing interventions specifically targeting rural men in these contexts via the Internet may be more sustainable compared to traditional HIV/STI prevention interventions among men that are delivered in physical spaces. Additionally it will be important to tailor any interventions aimed at rural men using the Internet to find sexual partners, particularly those with more sexually compulsive tendencies, to specifically address the issues of an area that has historically marginalized homosexuals and has limited resources to offer in terms of sexual heath.

These data should be considered in terms of limits inherent in a study that used convenience sampling, although the range of recruitment methods, particularly those on the Internet, sought to saturate the known venues (both physical and virtual) that are used by MSM in this area. Also, it is likely that some MSM were uncomfortable responding to a survey about their sexual behaviors, a challenge in research of this nature. Additionally, although this paper focuses on issues pertaining to MSM, heterosexual men were included in the analysis because the vast majority ( $85 \%$ ) of participants had visited a gay-related websites that may indicate that the men in this study were reluctant to identify as homosexual because of the sociocultural context of a rural midwestern town. Given that geographic context is important in the development of subcultures such as those created by MSM, care should be taken by practitioners to fully understand the context of where their interventions are occurring. In this case, rural men were more likely to access cruising spots and the Internet; therefore, in-person interventions may not be as effective in reaching individuals in contexts like these. Also, sexual compulsivity in this population may be indicative of the extra efforts MSM may have to go through in order to find community as well as sexual partners. Additionally, we should not begin to assume that Internet use is an outcome of sexual compulsivity, but may rather be a venue for all individuals living in rural areas especially for those groups that have historically been marginalized and stigmatized.

\section{Author Disclosure Statement}

No competing financial interests exist.

\section{References}

1. Gorbach P, Murphy R, Weiss R, Hucks-Ortiz C, Shoptaw S. Bridging sexual boundaries: Men who have sex with men and women in a street based sample in Los Angeles. J Urban Health 2009;86:63-76.

2. Scheer S, Kellogg T, Klausner J, et al. HIV is hyperendemic among men who have sex with men in San Francisco: 10year trends in HIV incidence, HIV prevalence, sexually transmitted infections and sexual risk behaviour. Sex Transm Infect 2008;84:493-498.

3. Jawanbakhy M, Murphy R, Harawa N, et al. Sexually transmitted infections and HIV prevalence among incarcerated men who have sex with men, 2000-2005. Sex Transm Dis 2009;36:S17-S21.

4. Osmond D, Pollack L, Paul J, Catania J. Changes in prevalence of HIV infection and sexual risk behavior in men who have sex with men in San Francisco: 1997-2002. Am J Public Health 2007;97:1677-1683.

5. Susan M. Estimation of HIV prevalence, risk factors, and testing frequency among sexually active men who have sex with men, aged 18-64 years-New York City, 2002. J Urban Health 2007;84:212-225.

6. Csatari J. AIDS update. Mens Health 1995;10:33.

7. Lieb S, Thompson D, Misra S, et al. Estimating populations of men who have sex with men in the southern United States. J Urban Health 2009;86:887-901.

8. Foster P, Gaskins S. Older African Americans' management of HIV/AIDS stigma. AIDS Care 2009;21:1306-1312. 
9. Stratford D, Ellerbrock T, Chamblee S. Social organization of sexual-economic networks and the persistence of HIV in a rural area in the USA. Cult Health Sex 2007;9:121-135.

10. Uphold C, Rane D, Reid K, Tomar S. Mental health differences between rural and urban men living with HIV infection in various age groups. J CommunHealth 2005;30:355-375.

11. Adimora A, Schoenbach V, Martinson F, Donaldson K, Stancil T, Fullilove R. Concurrent sexual partnerships among African Americans in the rural south. Ann Epidemiol 2004; 14:155.

12. Heckman T, Silverthorn M, Waltje A, Meyers M, Yarber W. HIV transmission risk practices in rural persons living with HIV disease. Sex Transm Dis 2003;30:134.

13. Heckman T, Somlai A, Peters J, et al. Barriers to care among persons living with HIV/AIDS in urban and rural areas. AIDS Care 1998;10:365-375.

14. Dodge B, Reece M, Cole SL, Sandfort TGM. Sexual compulsivity among heterosexual college students. J Sex Res 2004;41:343-350.

15. Fischer B. Sexual addiction revisited. Addict Newsl 1995;2:27.

16. Reece M. Sexual compulsivity and HIV serostatus disclosure among men who have sex with men. Sex Addict Compulsivity 2003;10:1-11.

17. Reece $M$, Dodge $B, M c B r i d e ~ K$. Sexual compulsivity: Issues and challenges. In: McAnulty R, Burnette M, eds. Sex and Sexuality. London: Praeger Press, 2006:213-231.

18. Society for the Advancement of Sexual Health. Sexual addiction. http://sash.net/content/view/24/39/ (Last accessed January 10, 2010).

19. Gold SN, Heffner CL. Sexual addiction: Many conceptions, minimal data. Clin Psychol Rev 1998;18:367-381.

20. Bancroft J, Vukadinovic Z. Sexual addiction, sexual compulsivity, sexual impulsivity, or what? Toward a theoretical model. J Sex Res 2004;41:225-234.

21. Barth RJ, Kinder BN. The mislabeling of sexual impulsivity. J Sex Marital Ther 1987;13:15-23.

22. Carnes P. Contrary to Love: Helping the Sexual Addict. City Center, MN: Hazeldon, 1989.

23. Coleman E. The obsessive-compulsive model for describing compulsive sexual Am J Prev Psychiatry Neurol 1990;2: 9-14.

24. Cooper A, Delmonico DL, Burg R. Cybersex users, abusers, and compulsives: New findings and implications. Sex Addict Compulsivity 2000;7:5-29.

25. Goodman A. Sexual addiction. In: Lowinson JH, Ruiz P, Millman RB, Langrod JG, eds. Substance Abuse: A Comprehensive Textbook, 4th ed. Philadelphia: Williams \& Wilkins, 2005:504-539.

26. Gullette DL, Lyons MA. Sexual sensation seeking, compulsivity, and HIV risk behaviors in college students. J Community Health Nurs 2005;22:47-60.

27. Kalichman SC, Cain D. The relationship between indicators of sexual compulsivity and high risk sexual practices among men and women receiving services from a sexually transmitted infection clinic. J Sex Res 2004;41:235-241.

28. Kalichman SC, Johnson JR, Adair V, Rompa D, Multhauf K, Kelly JA. Sexual sensation seeking: Scale development and predicting AIDS-risk behavior among homosexually active men. J Pers Assess 1994;62:385-397.

29. Kalichman SC, Rompa D. Sexual sensation seeking and sexual compulsivity scales: Reliability, validity, and predicting HIV risk behavior. J Pers Assess 1995;65:586-601.

30. McBride K, Reece M, Sander S. Predicting outcomes of sexual behavior. Intern J Sex Health 2008;19:51-62.
31. Reece M, Dodge B. A study in sexual health applying the principles of community-based participatory research. Arch Sex Behav 2004;33:235-247.

32. Reece M, Plate PL, Daughtry M. HIV prevention and sexual compulsivity: The need for an integrated strategy of public health and mental health. Sex Addict Compulsivity 2001;8: 157-167.

33. Semple SJ, Zians J, Grant I, Patterson TL. Sexual compulsivity in a sample of HIV-positive methamphetamine-using gay and bisexual men. AIDS Behav 2006;10:587-598.

34. McBride K, Reece M. Predicting negative outcomes of sexuality using the Compulsive Sexual Behavior Inventory. Int J Sexual Health 2008;15:97-115.

35. Satinsky S, Fisher C, Stupiansky N, Dodge B, Alexander A, Herbenick D, Reece M. Sexual compulsivity among men in a decentralized MSM community of the Midwestern United States. AIDS Patient Care STDs 2008;22:553-560.

36. Benotsch EG, Kalichman SC, Kelly JA. Sexual compulsivity and substance use in HIV-seropositive men who have sex with men: Prevalence and predictors of high-risk behaviors. Addict Behav 1999;24:857-868.

37. Kalichman S, Rompa D. Sexual sensation seeking and sexual compulsivity scales: validity, and predicting HIV risk behavior. J Person Assess 1995;65:586.

38. Benotsch EG, Kalichman SC, Pinkerton SD. Sexual compulsivity in HIV-positive men and women: Prevalence, predictors, and consequences of high-risk behaviors. Sex Addict Compulsivity 2001;8:83-99.

39. Bimbi DS, Nanin JE, Parsons JT, Vicioso KJ, Missildine W, Frost DM. Assessing gay and bisexual men's outcome expectancies for sexual risk under the influence of alcohol and drugs. Substance Use Misuse 2006;41:643-652.

40. Kalichman SC, Greenberg J, Abel GG. HIV-seropositive men who emerge in high-risk sexual behavior: Psychological characteristics and implications for prevention. AIDS Care 1997;9:441-450.

41. Kalichman SC, Rompa D. The sexual compulsivity scale: Further development and use with HIV-positive persons. J Pers Assess 2001;76:379-395.

42. Grov C, Bamonte A, Fuentes A, Parsons JT, Bimbi DS, Morgenstern J. Exploring the Internet's role in sexual compulsivity and out of control sexual thoughts/behaviour: A qualitative study of gay and bisexual men in New York City. Cult Health Sex 2007:1-19.

43. Parsons JT, Bimbi D, Halkitis PN. Sexual compulsivity among gay/bisexual male escorts who advertise on the Internet. Sex Addict Compulsivity 2001;8:101-112.

44. Parsons JT, Kelly BC, Bimbi DS, Muench F, Morgenstern J. Accounting for the social triggers of sexual compulsivity. J Addict Dis 2007;26:5-16.

45. Parsons JT, Severino JP, Grov C, Bimbi DS, Morgenstern J. Internet use among gay and bisexual men with compulsive sexual behavior. Sex Addict Compulsivity 2007;14:239-256.

46. Rosenmann A, Safir MP. Gay identity nonendorsement and the role of dissociative characteristics in a culturally diverse online sample of men who have sex with men. Sex Res Social Policy 2007;4:18-26.

47. Bowen A, Williams M, Daniel C, Clayton S. Internet based HIV prevention research targeting rural MSM: Feasibility, acceptability, and preliminary efficacy. J Behav Med 2008;31: $463-477$.

48. Horvath K, Rosser B, Remafedi G. Sexul risk taking among young internet-using men who have sex with men. Am J Public Health 2008;98:1059-1067. 
49. Ross M, Rosser B, McCurdy S, Feldman J. The advantages and limitations of seeking sex online: A comparison of reasons given for online and offline sexual liaisons by men who have sex with men. J Sex Res 2007;44:59-71.

50. Torres HL, Gore-Felton C. Compulsivity, substance use, and loneliness: The loneliness and sexual risk model (LSRM). Sex Addict Compulsivity 2007;14:63-75.

51. Kalman TP, Clinical encounters with Internet pornography. J Am Acad Psychoanal Dyn Psychiatry 2008;36:593-618.

52. Cooper A, Delmonico DL, Burg R. Cybersex users, abusers, compulsives: New findings and implications. Sexual Addict Compulsivity 2000;5:30.

53. Putnam DE. Initiation and maintenance of online sexual compulsivity: Implications for assessment and treatment. J Cyberpsychol Behav 2000;3:553-563.

54. Young KS, Griffin-Shelly E, Cooper A, O'Mara J, Buchanan J. Online infidelity: A new dimension in couple relationships with implications for evaluation and treatment. Sexual Addict Compulsivity 2000;59:74.

55. Al-Tayyib A, McFarlane M, Kachur R, Rietmeijer C. Finding sex partners on the internet: What is the risk for sexually transmitted infections? Sex Transm Infections 2009;85: 216-220.
56. Griffiths M. Excessive Internet use: Implications for sexual behavior. J Cyberpsychol 2000;3:537-552.

57. Griffiths M. Sex on the Internet: Observations and implications for Internet sex addiction. J Sex Res 2001;38:333-342.

58. Dew BJ, Chaney MP. Sexual addiction and the Internet: Implications for gay men. J Addict Offender Couns 2004;24: 101-114.

59. Reece M, Dodge B. A study in sexual health applying the principles of community-based participatory research. Arch Sex Behav 2004;33:235-247.

60. Isreal BA, Shulz AJ, Parker EA, Becker AB. Communitybased participatory research: Policy recommendations for promoting a partnership approach in health research. Educ Health 2001;14:182-197.

Address correspondence to: Phillip W. Schnarrs, M.A. Department of Applied Health Science Indiana University 1025 East Seventh Street, HPER 116 Bloomington, IN 47408

E-mail: pwschnar@indiana.edu 
